\title{
Rocket Propellants
}

Various types of propellants are used to launch rockets and missiles as well as drive projectiles from guns. A "propellant" is any solid, liquid, or gas fuel used to impart motion to another object. Propellants release energy in a system, with controlled thrust; many of these same energetic materials are also used as explosives. Solid or liquid propellants undergo a rapid chemical reaction that produces gaseous products that propel another object. For centuries, this principle has been used to shoot projectiles great distances.

With the invention of black powder, or gunpowder, in about the 11th century, the Chinese were the first to use rockets, primarily for pyrotechnic displays. By the year 1232, the Chinese had developed an arrow with a tube of gunpowder that could shoot fire across to an enemy army. The secret of gunpowder spread to the Arabs and Mongols, and within decades they too were using gunpowder-filled rockets in battle. In England in the middle of the 13th century, the monk Roger Bacon published the correct formula for gunpowder: a mixture of charcoal, sulfur, and potassium nitrate (saltpeter). This led, only a few decades later, to the development of the first firearms.

While black powder remained the primary rocket propellant, some early rockets made use of tar, pitch, sulfur, turpentine, naphtha, petroleum, and charcoal as propellants, usually with salt or saltpeter added to make the flame burn hotter. Early in the 19th century, Sir William Congreve encouraged extensive use of rockets in the British army. His new designs used a solid charge of black powder to increase the range from 600 feet (180 meters) to 9,000 feet $(2,700$ meters). Congreve's rockets were first used in the Napoleonic Wars against the cities of Boulogne (1805 and 1806), Danzig (1806), and Copenhagen (1807). In the mid-1800s, nitrocellulose, nitroglycerine, and dynamite were also used in rockets for warfare.

Partly spurred on by the fictional speculations of the French writer Jules Verne, theorists began to consider using rockets to journey into space. In a cell, awaiting execution for his part in the assassination of Tsar Alexander II in 1881, the Russian dissident Nikolai Ivanovitch Kibalchich drew up plans for a man-carrying rocket platform fed by gunpowder cartridges. After he was executed, guards filed his sketches in police archives, where they lay forgotten for many years. Independently, Konstantin Tsiolkovsky, a schoolteacher in Russia, in 1903 proposed using reaction-propulsion power for travel beyond the Earth's atmosphere and suggested using a liquid propellant for his rockets: a mixture of oxygen and hydrogen.

In 1919, Robert Hutchings Goddard, a physics professor in the United States, published A Method of Reaching Extreme Altitudes, which established many of the major principles of modern rocketry. Goddard worked with solid propellants for several years, developing a double-base powder of $40 \%$ nitroglycerine and $60 \%$ nitrocellulose, before switching his attention to liquid propellants in 1923. In Massachusetts, on March 16, 1926, Goddard launched the first liquid oxygen and gasoline rocket, which reached a height of 184 feet (56 meters) and a speed of 64 miles (103 $\mathrm{km})$ per hour. Although his experiment was a success, the pyrotechnics alarmed the locals, and Goddard was banned from conducting further rocket flights in the area. His work, however, attracted the attention of Col. Charles A. Lindbergh and the Guggenheim foundation; they funded his further work and persuaded him to move his tests to Roswell, New Mexico.

During World War II, the United States, Britain, the Soviet Union, and Japan developed many new designs of solidpropellant military rockets. In Germany, however, a team of rocket scientists including Walter Dornberger and Wernher von Braun worked on both liquid- and solidpropellant rocket vehicles. Liquid propellants generally provide a higher specific impulse, and they are also more versatile in rocket applications since throttling is possible and liquid-propellant engines can be checked and calibrated precisely before launch; it is also possible to restart liquidfueled rocket engines. Unfortunately, liquid-propellant systems are more complex, less reliable, and less rugged than solid-propellant systems.

Some small German rockets were propelled with nitric acid and a hydrocarbon mixture; the V-2 (also called A-4) rockets were propelled with a mixture of liquid oxygen and $75 \%$ ethyl alcohol. The V-2 development began in the late 1930s in the isolated test installation of Peenemünde in northern Germany, and the first launch took place in 1942. After two fiery failures, the third test launch sent a rocket to a height of 53 miles $(85 \mathrm{~km})$ and a distance of 118 miles $(190 \mathrm{~km})$. The first $\mathrm{V}-2$ rocket was launched against London near the end of the war, on September 7, 1944; the V-2's liftoff thrust reached 56,000 pounds. After the war, many of the German rocket scientists were incorporated into the U.S. and Soviet rocket programs. Their work made possible the use of rockets for actual space flight.

In a rocket engine, the combustion of the propellants produces hot gases that are exhausted through a nozzle in the rear, providing thrust. Combustion requires both fuel and an oxidizer; in jet engines, for example, the fuel is carried along with the craft, while the oxidizer-air-is obtained by the engine in flight. A rocket in space, however, must carry its own oxidizer, since it flies through a vacuum. Bringing the oxidizer along as part of the rocket propellant, the rocket is able to perform better in the vacuum without atmospheric drag on the craft and without air to dampen the exhaust gases and prevent them from reaching their maximum velocity.

The rockets in the U.S. Apollo program from the 1960s to 1970s used a fuel of specialized kerosine (RP-1) and an oxidizer of liquid oxygen (giving a specific impulse of 293 s). This combination was readily available and economical, providing fairly high performance. In the Apollo craft, the five first-stage engines burned for 2.5 minutes-consuming 560,000 gallons $(2,120,000$ liters $)$ of fuel to accelerate the rocket to 6,000 miles $(9,600 \mathrm{~km})$ per hour and to a height of 41 miles $(66 \mathrm{~km})$. The second stage used a fuel of liquid hydrogen and liquid oxygen as an oxidizer (with a higher specific impulse of $387 \mathrm{~s}$ ).

The U.S. Space Shuttle also uses the high-specific-impulse liquid hydrogen and liquid oxygen for its main engines, assisted by two solid-propellant rocket boosters. Other rocket vehicles use these and other propellants, including hydrazine $\left(\mathrm{N}_{2} \mathrm{H}_{4}\right)$ with a specific impulse of $\sim 287 \mathrm{~s}$, monomethyl hydrazine (specific impulse of 283 s), dimethyl hydrazine (specific impulse of $282 \mathrm{~s}$ ), or solid synthetic rubbers known as Thiokols (specific impulse ranging from 170 to $210 \mathrm{~s}$ ), mixed with various oxidizers such as chlorine trifluoride, nitrogen tetroxide, and red fuming nitric acid.

Alternative concepts in rocket propellants have been considered over the past several decades, some of which continue to show great promise. These include the nuclear fission rocket (studied extensively in the 1960s, and recently the subject of renewed interest), the plasma rocket, magnetohydrodynamic drives, ion drives, and photon (or laser) drives. As we continue to probe deeper into space, different types of rocket propellants and rocket designs will be needed to satisfy our diverse requirements, from large, heavy, cargo-lifting vehicles to delicate attitude-control rockets.

KEVIN J. ANDERSON 


\section{Encyclopedia of Applied Physics}

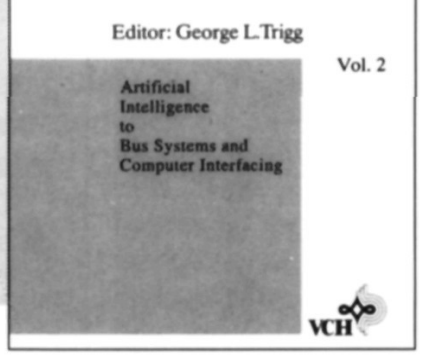

"Exclusively devoted to the technical and industrial applications of physics"

The 20-volume Encyclopedia of Applied Physics, edited by G. L. Trigg, contains 500 alphabetically arranged, in-depth articles on the most relevant current and future applications of physics.

More technical than a general purpose encyclopedia, this reference work will prove invaluable not only to physicists and engineers, but also to scientists in associated areas.

A major scientific undertaking, the Encyclopedia of Applied Physics is sponsored by the physical societies of various countries, e.g., the American Institute of Physics.

Coverage ranges from general devices and laboratory methods through condensed matter physics to aeronautics and space physics.

Cumulated subject indexes are published after every three volumes. The series can only be purchased as a complete set.

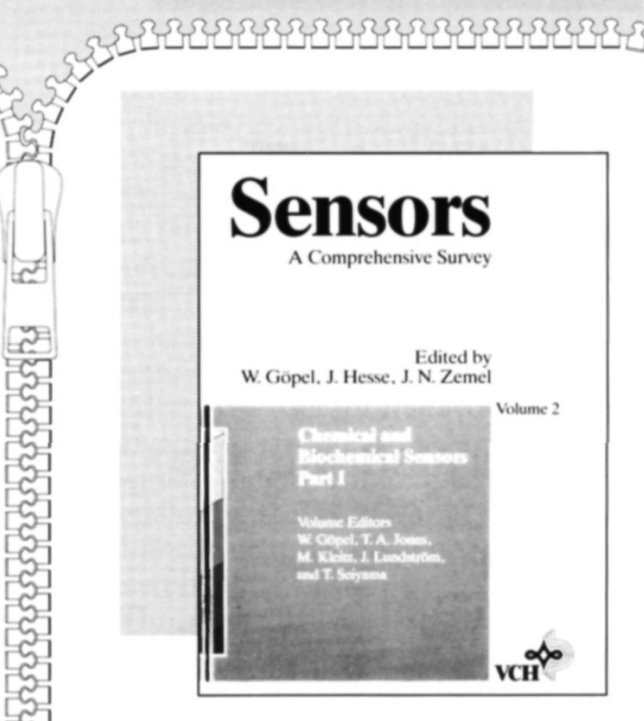

"Meeting the varying needs of the sensor community"

Sensors are a key element in the rapidly evolving field of measurement and instrumentation.

Each of the 8 volumes of the series Sensors - A Comprehensive Survey consists of three parts: specific physical and technological fundamentals and relevant measuring parameters; types of sensors and their technologies; and the most important applications with a discussion of emerging trends.

The volumes concentrate on Fundamentals (Vol. 1), Chemical \& Biochemical Sensors (Vols. 2/3), and Thermal (Vol. 4), Magnetic (Vol.5), Optical (Vol. 6), and Mechanical (Vol. 7) Sensors with a cumulative index (Vol. 8).

Series editors are W. Göpel, J. Hesse, and J.N. Zemel, and the volume editors and authors are internationally renowned experts.

The series can be purchased as a complete set or by volume.

Circle No. 21 on Reader Service Card.

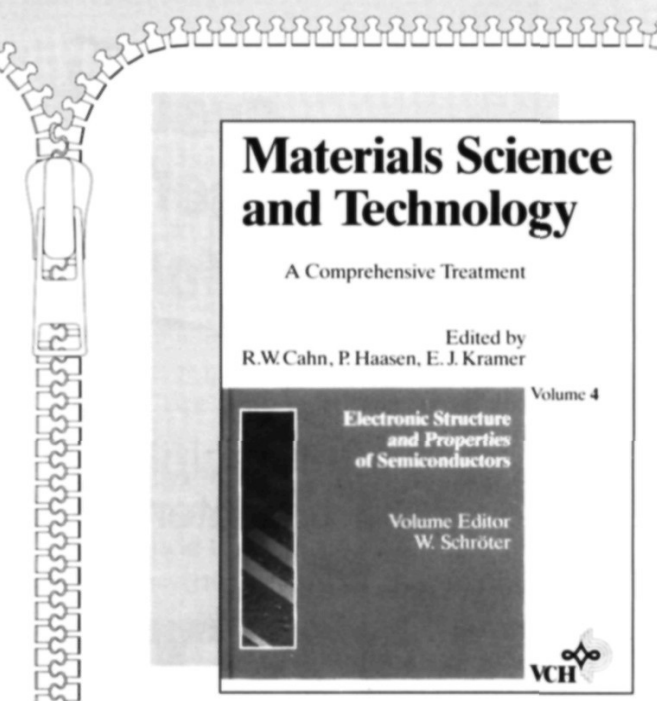

"Sure to establish itself as a seminal work."

The phenomenal turnout of new products in all industries, from conventional to high-tech, owes its success largely to intensified efforts in materials research and development. The 18-volume series Materials Science and Technology - A Comprehensive Treatment is an in-depth, topic-oriented reference work created specifically to further these efforts.

The series covers the most important classes of materials: metals, ceramics, glasses, polymers, semiconductors, and composites.

Each volume deals with properties, processing, applications, or general phenomena associated with the above-mentioned materials.

Edited by R.W. Cahn, P. Haasen, and E.J. Kramer, the series began publication in 1990 and is proceeding at a rate of four to five volumes per year, each volume containing 10 to 20 contributions and averaging 500 pages. The series can be purchased as a complete set or by volumes

VCH, Attn. Sabine Bischoff,

P. O. Box 101161, D-6940 Weinheim (FRG and all other countries)

Fax: 0049-6201-606328

$\mathrm{VCH}$, Hardstrasse 10 , $\mathrm{CH}-4020$ Basel (Switzerland)

Fax: 0041-61-2710618

$\mathrm{VCH}, 220$ East 23rd Street, New York, NY 10010-4606 (USA and Canada)

Fax: 001-212-481-0897

$\mathrm{VCH}, 8$ Wellington Court, Cambridge CB1 $1 \mathrm{HZ}$ (UK) Fax: 0044-223-313321

\section{Sensors}



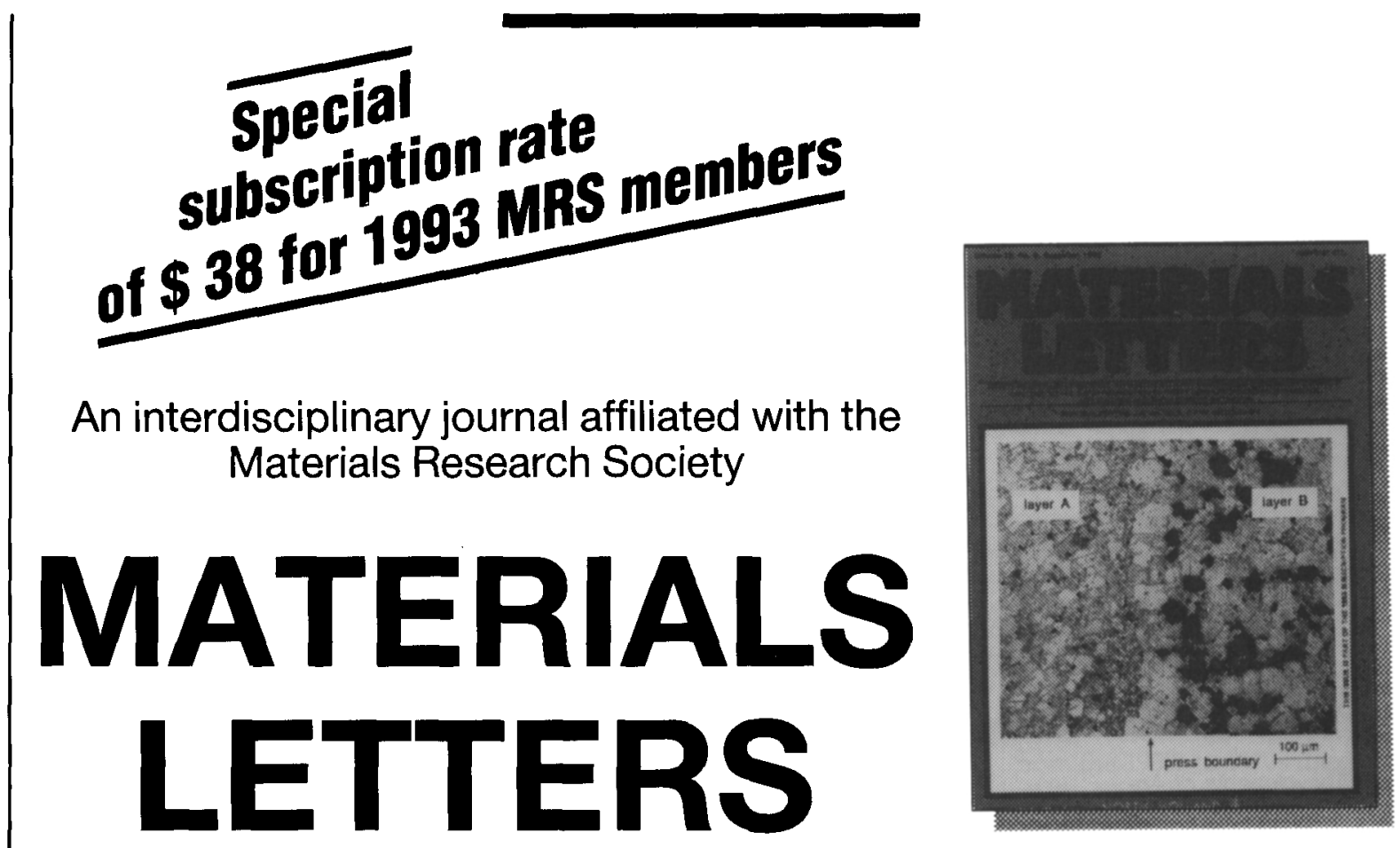

Devoted to the rapid publication of short communications on the science, applications and processing of materials

\section{Covering Materials Science in} its broadest sense

Materials Letters is an

interdisciplinary journal devoted to the rapid publication of letter type papers. The scope of the journal covers the area of materials science in its broadest sense, ranging from solid state physics to materials technology. Important topics include:

- Preparation and Characterization of Materials

- High-Tc Superconductivity

- Preparation, Characterization and Physics of Semiconductors

- Thin Films

- Physical Metallurgy, Mechanical Properties, Ceramics and Composites.

Materials Letters has been affiliated with the Materials Research Society since the early years of the journal, and a significant number of the editorial board members are MRS representatives.
Subscription Information: 1993: Volumes 15-18 (in 24 issues) Price: US\$887.00 / Dfl. 1552.00 including postage and handling costs ISSN 0167-577X

\section{Elsevier Science Publishers BV}

P.O. Box 103, 1000 AC Amsterdam

The Netherlands

Tel: (31) 205862819

Fax: (31) 205862580

\section{In USAVanada}

Elsevier Science Publishers

Journals Information Center

655 Avenue of the Americas

New York, NY 10010, USA

Tel (212) 6333950

Fax: (212) 6333764

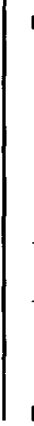

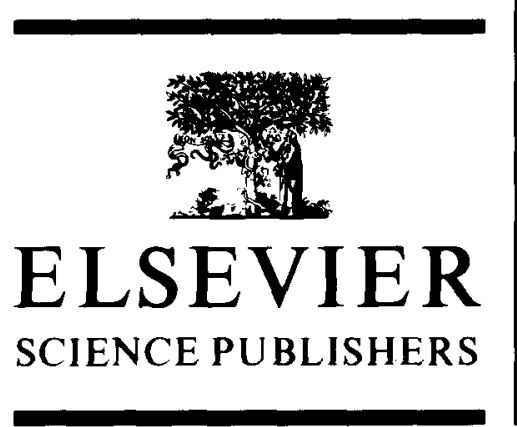

Please visit Booth Nos. 204-208 at the MRS Exhibit in San Francisco, April 13-15, 1993.
Principal Editors:

J.H. Wernick, AT\&T Bell Laboratories, Murray Hill, USA

\section{A.F.W. Willoughby,} The University of Southampton, Southampton, UK

For:

- Materials scientists

- Metallurgists

- Solid state chemists

- Physicists

The Dutch Guiler (Dfl.) price is definitive. US $\$$ is subject to exchange rate fluctuations. Customers in the European Community should add the appropiate VAT rate applicable in their country to the price(s)

Visit our booth during the MRS spring meeting and pick up your free sample copy

Circle No. 22 on Reader Service Card. 